\title{
Renewable Energy Perspective for Turkey Using Sustainability Indicators
}

\author{
Burcu Kuleli Pak \\ Department of Industrial Engineering, Dogus University, Zeamet Sok.No:21 Kadikoy Istanbul, 34722, Turkey, \\ Email:bkuleli@dogus.edu.tr \\ Tel: 00902163271104, Fax: 0090216544553 \\ www.dogus.edu.tr \\ Yildiz E. Albayrak \\ Department of Industrial Engineering, Galatasaray University, Çırağan Cad. No: 36 Ortaköy Istanbul, 34357, \\ Turkey, \\ Email: ealbayrak@gsu.edu.tr \\ Yasemin C. Erensal \\ Department of Industrial Engineering, Okan University Tuzla Campus, Istanbul, 34959, Turkey, \\ Email:yerensal@gmail.com
}

Received 9 December 2013

Accepted 31 August 2014

\begin{abstract}
Energy indicators for sustainable development which were introduced by the International Atomic Energy Agency in 2005 were used in this study to determine a renewable energy perspective for Turkey. The decision making includes social, economic, and environmental factors which affect each other resulting in a multi-criteria decision making problem. The problem is modeled integrating the technique of Analytic Network Process and TOPSIS. Also a sensitivity analysis is performed to monitor the influence of criteria weights on the model results.
\end{abstract}

Keywords: Analytic Network Process, TOPSIS, Multiple Criteria Decision Making, Energy Planning

\section{Introduction}

Sustainable development is economically and environmentally improving quality of life over the long term in a way that can be sustained and must be supported by the institutional structure of a country. The term sustainable development includes improving social and economic wellbeing, industrial and commercial wealth generation, relieving poverty, improving human welfare and raising living standards. Energy is central to these processes [1].

Sustainability and sustainable development concepts have common-place both in corporate and environmental policy literature. Sustainable energy systems should deliver affordable services while raising the population's standard of living. In order to make the system sustainable, diversification and localization of energy sources is needed together with ensuring that the impact of using each source is within environmental limits. The renewability of a fuel does not make a system sustainable. Waste, flexibility, energy security and independence issues must also be taken into consideration. "Sustainability is non-declining human well-being over time" [2].

Delivering affordable energy services while raising the living standard of the global population by increasing energy efficiency and deployment of renewables is the goal of sustainable energy systems. Deployment of renewable can also contribute to mitigating the emissions of 
greenhouse gases (GHG) and enhancing energy security of supply and independence [3].

Negative effects of fossil fuels on the environment are known and awareness by authorities of environmental issues is rising. Developing countries especially are forced to use renewable energy alternatives because of the precarious nature of dependency on fossil fuel imports. Renewable energy alternatives are environment friendly and they are capable of replacing conventional sources at competitive prices [4]. Also the finite nature of fossil fuels and upward trends in their prices make them unsustainable.

In Turkey, while the share of native energy generation decreased, the amount of imported energy rapidly increased from the 90's to today. Approximately $74 \%$ of total energy supply for Turkey's energy demand is met by imports. For sustainable development in both the national and global scale, different middle and long-term alternatives which enable increasing energy source variations and decreasing the dependence on the foreign supply must be considered. The native and renewable energy sources have to be evaluated in a sensitive way and they must be promoted from an environmental point of view.

There is a gap between the goals of sustainable development and Turkey's energy policies. For sustainable development, determining the appropriate energy policy that will define energy source combination to use in the following years is an obligation for Turkey. This policy determination issue is a multi-criteria decision making (MCDM) problem. Although energy planning using multicriteria analysis has attracted the attention of decision makers for some time, scientists have not paid sufficient attention to determination of energy indicators for sustainable development and building a model using them. Although energy system is a reliable framework for providing lead indicators for sustainable development, there is no article in the literature regarding Turkey that tries to measure the energy system's sustainability or build a renewable energy perspective quantitatively using Energy Indicators for Sustainable Development (EISD) to the best of our knowledge.

The model was built using both the reports of international energy organizations and opinions of experts'. Analytic Network Process is used in this article as the model because of its capability to include dependencies and feedbacks between indicators opposed to many MCDM methods based on independence assumption. The model includes both the quantitative values and the experts' projections and experiences. ANP is also capable of including qualitative judgments [5].

As indicated in [6] there are many different Multiple Attribute Decision Making (MADM) problems and many MADM methods to solve them. Different scoring methods were compared in the same decision making environment and no significant difference could be found in terms of the appropriateness of the method and ease of use [6]. Thus TOPSIS is preferred as an outranking method in this work because of its rational logic and understandability. Its computation process is uncomplicated and it allows us to utilize importance weights in comparison and ranking. Using ANP and TOPSIS together, our results passed through the filter of these two methods.

This paper proposes a renewable energy perspective for Turkey using a five-phase decision making framework that integrates Analytic Network Process (ANP) and Technique for Order Preference by Similarity to Ideal Solution (TOPSIS) techniques. The ANP model is used to determine criteria weights and the TOPSIS model is used to rank alternatives. However the entire ANP model was not evaluated in order to eliminate time-consuming pair wise comparisons and calculations. This perspective is proposed to decrease import dependency of the country and promote the electricity produced from renewable sources which is a target of the European Union.

The remainder of this paper is structured as follows: Section 2 presents the decision making frame work proposed to determine a renewable energy perspective for Turkey and introduces ANP and TOPSIS methods. In section 3, the potentials of available renewable energy resources in Turkey are presented. Energy indicators for sustainable development which were used as the evaluation criteria are presented and the relationship among them are given in section 4 . The numeric values of the evaluation criteria are given in section 5 . The case study and preference rankings are given in section 6. A sensitivity analysis is conducted to observe the sensitivity of the results with respect to changes in criteria weights in section 7 and finally the results are discussed in section 8 . 


\section{Proposed decision making framework}

The decision making framework proposed in this paper is presented step by step in Figure 1. The study began with determination of evaluation criteria. Energy indicators for sustainable development defined by [1] were used, however the full set of indicators were not used. The selected indicators that will make a distinguishing impact for renewable energy resources were used and selection was made as result of interviews with energy sector experts.

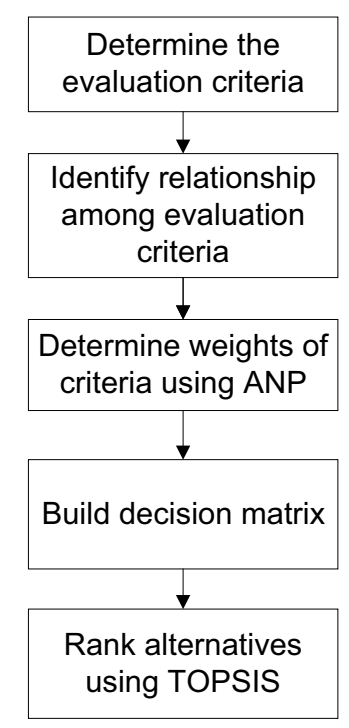

Fig. 1. Overall procedure for renewable energy perspective problem

In order to identify the relationship among evaluation criteria both the reports of international agencies and interviews with experts were considered. Subsequently, the criteria weights were defined using ANP and alternatives were ranked using TOPSIS. The study was followed by the sensitivity analysis.

\subsection{Criteria weight determination using ANP}

The relative importance of evaluation criteria was determined using the ANP method developed by Thomas Saaty [5] and is a generalization of the Analytic Hierarchy Process (AHP) method [7]. AHP is limited to relatively static and unidirectional interactions with little feedback among decision components and alternatives [8]. This weakness can be overcome by using ANP, the advanced multi-criteria making technique.

Many real life decision problems cannot be structured as a hierarchy because of the fact that these problems involve the interaction and dependence of higher level elements in a hierarchy on lower level elements. So the hierarchy becomes more like a network [9]. In this context, ANP and its super-matrix technique can be considered as an extension of AHP that can handle a more complex decision structure $[5,10]$. As the ANP framework has the flexibility to consider more complex interrelationships (outer-dependence) among different elements. ANP is very useful in these kinds of situations providing a general framework without the assumptions of independence of higher-level elements from lower ones, or independence on the same level [5].

The entire ANP model was not evaluated in order to eliminate time-consuming pairwise comparisons and calculations. Also, due to the structure of relationship among evaluation criteria, the following modified ANP procedure which was proposed by Huan-Jyh Shyur [11] was used:

(i) The decision makers were asked to evaluate all proposed criteria pairwise without assuming the interdependence among criteria according to Saaty's 1-9 scale. They responded questions such as: "which criteria should be emphasized more in sustainable energy production, and how much more?" This comparison is made for each pair of criteria only once. The reciprocals of the values are used for reverse comparisons. Pairwise comparisons are represented by matrix A. After matrix A is completed, the local priority vector $\mathrm{w}_{1}$ is computed using the following formula

$$
A w_{1}=\lambda_{\max } w_{1},
$$

where $\lambda_{\max }$ is the largest eigenvalue of matrix A. Finally $\mathrm{w}_{1}$ vector is normalized by dividing each value by its column total and the normalized local priority vector $\mathrm{w}_{2}$ is obtained.

(ii) The interdependence of evaluation criteria were also handled by using pairwise comparisons. Questions such as: "Which criterion will influence criterion CC more: EU or SE? And how much more?" are answered. Then pairwise comparison matrices were used to identify the relative impacts of criteria interdependent relationships and the normalized principal eigenvectors of these matrices are calculated. The eigenvectors are used as column components in interdependence weight matrix of criteria B.

(iii) Finally the interdependence priorities of the criteria were calculated using the following formula:

$$
w_{c}=B w_{2}^{T}
$$




\subsection{TOPSIS}

The Technique for Order Preference by Similarity to Ideal Solution (TOPSIS) was developed by Hwang and Yoon [12] in 1981. The method is based on the selection of alternative that have the shortest distance from the ideal solution and longest distance from the negative-ideal solution geometrically. Euclidean distance is used to measure the relative closeness of alternatives to the ideal solutions and preference order of alternatives is derived the comparisons of these distances. The TOPSIS method includes the following steps [13];

(i) Construct normalized decision matrix R: Firstly various criteria dimensions are converted into non-dimensional criteria. The elements of $\mathrm{R}$ are calculated by the following formula;

$r_{i j}=\frac{x_{i j}}{\sqrt{\sum_{k=1}^{m} x_{k j}^{2}}}$

Where $\mathrm{x}_{\mathrm{ij}}$ denotes the performance measure of the $i^{\text {th }}$ alternative in terms of $j^{\text {th }}$ criterion. In the TOPSIS method, some other alternative distance measures can be used which results in different answers for the same problem.

(ii) Construct the weighted normalized decision matrix: A set of weights must be defined by the decision maker as $\mathrm{W}=\left(\mathrm{w}_{1}, \mathrm{w}_{2}, \ldots, \mathrm{w}_{\mathrm{n}}\right)$ and $\sum w_{i}=1$. The weighted normalized matrix $\mathrm{V}$ is formed as follows;

$$
V=\left[\begin{array}{ccc}
w_{1} r_{11} & \cdots & w_{n} r_{1 n} \\
\vdots & \ddots & \vdots \\
w_{1} r_{m 1} & \cdots & w_{n} r_{m n}
\end{array}\right]
$$

(iii) Determine the ideal and the negative-ideal solutions: The ideal $\left(\mathrm{A}^{*}\right)$ and negative ideal $\left(\mathrm{A}^{-}\right)$solutions are defined as follows;

$$
\begin{aligned}
& A^{*}=\left\{\left(\max _{i} v_{i j} \mid j \in J\right),\left(\min _{i} v_{i j} \mid j \in J^{\prime}\right), i=\right. \\
& 1,2,3, \ldots, m\}=\left\{v_{1^{*}}, v_{2^{*}}, \ldots, v_{n^{*}}\right\} \\
& A^{-}=\left\{\left(\min _{i} v_{i j} \mid j \in J\right),\left(\max _{i} v_{i j} \mid j \in J^{\prime}\right), i=\right. \\
& 1,2,3, \ldots, m\}=\left\{v_{1^{-}}, v_{2^{-}}, \ldots, v_{n^{-}}\right\} \\
& \text {Where: } J=\left\{\begin{array}{c}
j=1,2,3, \ldots, n \\
\text { and } j \text { is associated with } \\
\text { benefit criteria }
\end{array}\right\} \\
& J^{\prime}=\left\{\begin{array}{c}
1,2,3, \ldots, \text { n and } j \text { is associated with } \\
\text { cost }- \text { loss criteria }
\end{array}\right\}
\end{aligned}
$$

Here it is important to assume that the decision maker wants to select the alternative with maximum value for benefits criteria and the alternative with minimum value for cost/loss criteria. So the ideal solution is the most preferable and negative ideal solution is the least preferable alternative. (iv) Calculate the separation measure: The distances of each alternative from ideal and negative ideal solution is calculated using Euclidean distance method. So that the distances from ideal solution and negative ideal solution are calculated by;

$S_{i^{*}}=\sqrt{\sum_{j=1}^{n}\left(v_{i j}-v_{j^{*}}\right)^{2}}$, for $\mathrm{i}=1,2,3, \ldots, \mathrm{m}$,

where $\mathrm{S}_{\mathrm{i}^{*}}$ is the distance of each alternative from the ideal solution.

$S_{i^{-}}=\sqrt{\sum_{j=1}^{n}\left(v_{i j}-v_{j^{-}}\right)^{2}}$ for $\mathrm{i}=1,2,3, \ldots, \mathrm{m}$,

where $\mathrm{S}_{\mathrm{i}-}$ is the distance of each alternative from the negative ideal solution.

(v) Calculate the relative closeness to the ideal solution: The relative closeness of an alternative $A_{i}$ with respect to the ideal solution $\mathrm{A}^{*}$ is defined as follows:

$C_{i^{*}}=\frac{S_{i-}}{S_{i *}+S_{i-}}$,

where $1 \geq C_{i *} \geq 0$, and $\mathrm{i}=1,2,3, \ldots, \mathrm{m}$.

Apparently, $\mathrm{C}_{\mathrm{i}^{*}}=1$, if $\mathrm{A}_{\mathrm{i}}=\mathrm{A}^{*}$, and $\mathrm{C}_{\mathrm{i}}=0$, if $\mathrm{A}_{\mathrm{i}}=\mathrm{A}^{-}$.

(vi) Rank the preference order: The optimal alternative can now be decided. It is the one that has the shortest distance to the ideal solution. Also remember that any alternative that has the shortest distance to the ideal solution is guaranteed to have the longest distance to the negative ideal solution.

\section{Energy Resources Potential}

All kinds of energy sources are available in Turkey, but power plants currently in use are not sufficient to meet the energy requirement of the country. Hence, Turkey imports more than half of its required energy supply [14]. Renewable energy resources may be suitable for energy production in Turkey but they differ in their capacities for power generation, suitability of potential site, sustainability and stability of energy resource, etc. The potentials of available renewable energy resources in Turkey can be summarized as such;

Biomass: In 1998, Turkey's total recoverable bioenergy potential was calculated as $196.7 \mathrm{TWh}$ (16.92 Mtoe). 55.9 TWh (4.81 Mtoe) of this potential was from crop residues, $50 \mathrm{TWh}$ (43 Mtoe) was from forestry and wood processing residues, 48.3 TWh (41.6 Mtoe) was from firewood, 27.3 TWh (23.5 Mtoe) was from animal 
wastes, and 15.1 TWh (13 Mtoe) was from municipality wastes [15].

Geothermal: Turkey's theoretical geothermal energy potential is acknowledged as $31500 \mathrm{MWt}$ and with this potential Turkey has one-eighth of the world's geothermal potential and is ranked 7th in the world and 1st in Europe [16].

Hydropower: The theoretical hydraulic energy potential of Turkey is about $1 \%$ of world potential, while it is $16 \%$ of European potential $[14,17]$, but nearly $65 \%$ of hydroelectric potential are still not converted to energy [15]. The gross annual hydro potential (theoretical hydroelectric potential with available water sources) of Turkey is $433,000 \mathrm{GWh}$ $[15,17]$.

Solar: the technical solar energy potential is $6105 \mathrm{TWh} /$ year which is very high in terms of electricity production [14]. Turkey's average sunbath time is $2640 \mathrm{~h}$ per day (daily total $7.2 \mathrm{~h}$ ) and average radiation volume is $1311 \mathrm{kWh} / \mathrm{m} 2$ per year (daily total $3.6 \mathrm{kWh} / \mathrm{m} 2$ ) [15].

Wind: Dundar et al. [18] have determined the technical potential of Turkey as $88 \mathrm{GW}$ in their wind atlas. Ogulata [19] has determined this value as $83 \mathrm{GW}$. Theoretically this potential can compensate the total electrical power necessity [15]. According to a study conducted by Greenpeace, Turkey's gross wind energy potential has been estimated as 400 billion $\mathrm{kW} \mathrm{h/year} \mathrm{and}$ technical potential has been estimated as 120 billion $\mathrm{kW} \mathrm{h}$ /year which is equal to 1.2 times of the current annual electricity production of Turkey [17] although currently only $2 \%$ of wind potential can be captured [15].

\section{Evaluation criteria and relationship}

In 1995, the United Nations Department of Economic and Social Affairs (UNDESA) began working on defining a set of sustainable development indicators as a response to decisions taken by the United Nations Commission on Sustainable Development (CSD) and Chapter 40 of Agenda 21. As a result of this effort 58 sustainable development indicators were defined. However only three of these were energy related; namely, annual energy consumption per capita, intensity of energy use, and share of consumption of renewable energy resources [20].

The study of defining energy indicators for sustainable development was initiated by
International Atomic Energy Agency (IAEA) in 1999. The process of selecting, defining and validating an appropriate set of energy-related indicators began with their study consonant with the larger effort on Indicators of Sustainable Development (ISD), which was developed by Member States of the United Nations and international organizations under the umbrella of Agenda 21 and the United Nations CSD. IAEA and International Energy Agency (IEA) cooperation presented their preliminary work in the 9th session of the CSD in 2001. This was followed by an international partnership created in 2002 to refine the energy indicators and was registered with the World Summit on Sustainable Development and the final form of the indicators were reported in 2005 by IAEA, UNDESA, IEA, Eurostat and European Environment Agency (EEA) [1].

In both [20] and [1] it was mentioned that countries do not have to use the full set of indicators. Depending on country specific conditions, they may use a selected set of indicators. Further they are not limited with the defined set of indicators, they are free to create other indicators. Unfortunately, there is no commonly accepted or standardized way of selecting an optimal set of indicators in the literature [21].

Although there are 30 indicators defined in [1], in this study only the selected indicators that will make a significant impact for renewable energy resources were used. The indicators which were selected for use as criteria in the proposed model are;

- Accident fatalities (AF)

- Energy use per capita (and per unit of GDP) (EU)

- Supply efficiency of energy (SE)

- Net import dependency (ID)

- Climate change (CC)

- Water quality (WQ)

- Soil area where acidification exceeds critical load. (SA)

The relationship among criteria which was defined as a result of literature survey and interviews was given in Figure 2. The arrows imply the relationship. For example, an arrow from EU to AF means the attributes of energy use influence the attributes of accident fatalities. 


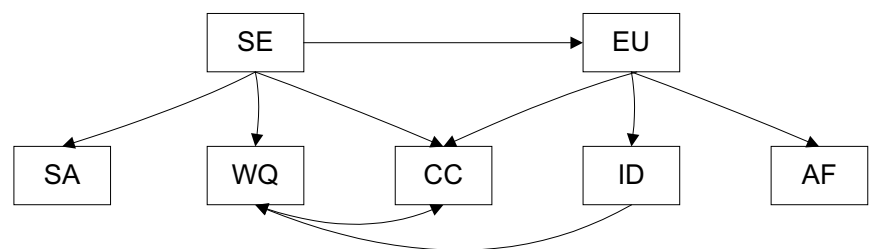

Fig. 2. Relationship among criteria

As previously indicated, the weights of criteria were determined using the modified ANP method.

To construct the decision matrix, the values of criteria by alternative were researched. The values for accident fatalities, supply efficiency, climate change, water quality and soil acidification could be found. The contributions of alternatives to energy use and import dependency criteria were determined by ANP technique.

\section{Decision matrix values}

The accident fatalities indicator was defined as number of annual fatalities per energy produced by fuel chain, but it was found more appropriate to use fatalities per TWh. The accidents occurred during the whole cycle until year 2008 was indicated by Gipe [22] and they are given in Table 1.

Table 1: Accident fatalities per energy produced by fuel chain

\begin{tabular}{ll}
\hline Energy Source & Death Rate (deaths per TWh) \\
\hline Biofuel/Biomass & 12 \\
Solar & $\begin{array}{l}0.44 \text { (less than } 0.1 \% \text { of world } \\
\text { energy) }\end{array}$ \\
Wind & $\begin{array}{l}0.15(\text { less than } 1 \% \text { of world } \\
\text { energy) }\end{array}$ \\
& 1.4 (about $2500 \mathrm{TWh} / \mathrm{yr}$. and \\
Hydro - world & $171,000 \mathrm{Banqiao} \mathrm{dead})$ \\
\hline
\end{tabular}

Energy use per capita is the proportion of total primary energy supply, total final consumption or electricity use to total population. Final inland consumption per capita is $1421 \mathrm{koe} / \mathrm{cap}$. and final electricity consumption per capita is 2256 $\mathrm{kWh} / \mathrm{cap}$. for Turkey [23]. Gross inland consumption of energy per GDP was 245.32 koe/1000 euros in 2008 [24].

Energy efficiency as a separate indicator can be defined as the useful energy that can be obtained from an energy source. The average efficiency coefficients calculated by [25] was given in Table 2.

Table 2: The average energy efficiency coefficients for power plants types

\begin{tabular}{ll}
\hline Type of power plant & Efficiency coefficient (\%) \\
\hline Hydro & 80 \\
Wind & 35 \\
Photovoltaic & 9.4 \\
Biomass & 28 \\
Geothermal & 6 \\
\hline
\end{tabular}

Although Turkey as a country has the potentials to utilize renewable energy resources, know-how and technology must be transferred from other countries. So import dependency of the resources was evaluated using ANP methodology.

Climate was handled by using global warming impact by fuel type. Water quality is defined as contaminant discharges in liquid effluents from energy systems including oil discharges and eutrophication impact by fuel type is used to measure it. For soil acidification, acidification impact by fuel type is used. Impact assessment results of electricity systems calculated by [26] using lifecycle assessment method were given in Table 3 .

Table 3: Environmental impacts of energy production technologies-

\begin{tabular}{lllll}
\hline Technology & Capacity/configuration/fuel & $\begin{array}{l}\text { Global warming } \\
\text { impact (g/kwh) }\end{array}$ & $\begin{array}{l}\text { Acidification } \\
\text { impact (mg/kwh) }\end{array}$ & $\begin{array}{l}\text { Eutrophication } \\
\text { impact (mg/kwh) }\end{array}$ \\
\hline Biomass & Waste wood steam turbine & 37 & 1288 & 172 \\
Geothermal & $80 \mathrm{MW}$, hot dry rock & 41 & 190 & 24,80 \\
Hydroelectric & $300 \mathrm{~kW}$, run-of-river & 13 & 61 & 6 \\
Solar (PV) & Polycrystalline silicone & 104 & 528 & 44 \\
Wind & $1.5 \mathrm{MW}$, onshore & 11 & 61 & 4 \\
\hline
\end{tabular}


All the countries have different conditions such as economic circumstances, geography, energy resources, etc. and the relative importance of the indicators may change depending on the country specific conditions, national energy priorities and sustainability objectives. So that, each country must find its own way to use the indicators. The implementation process will be shaped by national policy goals, existing statistical capabilities and expertise, and the availability and quality of energy and other relevant data [1]. In this study, ANP is used to handle the relative importance of indicators and TOPSIS is used to rank them and build up a sustainable energy plan for Turkey.

\section{The case study}

To assess sustainability of renewable energy resources, a case study was realized in this section. The group decision of five experts was used to complete the ANP steps. First, experts were asked to compare all proposed criteria pairwise without assuming the interdependence among criteria. Then the local priority vector is computed and normalized. The results can be seen in Table 4 . Consistency ratio (CR) is used to estimate the consistency of the pairwise comparisons. It is computed by taking the ratio of its consistency index $(\mathrm{CI})$ to the corresponding random index (RI) value. $\mathrm{CI}$, is the measure of inconsistency, is calculated using the following formula:

$\mathrm{CI}=\lambda_{\max }-\mathrm{n} / \mathrm{n}-1$

As indicated by [27] allowable CR value should be less than 0.1 and it can be said that our comparisons are acceptable.

Secondly the experts were asked to evaluate the impact of all the criteria on each other by using pairwise comparisons to include the effect of interdependence among criteria. The normalized principal eigenvectors for various pairwise comparison matrices are calculated and shown as column component in Table 5 .

Table 4: Pair wise comparison matrix of evaluation criteria

\begin{tabular}{|c|c|c|c|c|c|c|c|c|}
\hline & $\mathbf{A F}$ & $\mathbf{E U}$ & SE & ID & $\mathrm{CC}$ & WQ & $\mathbf{S A}$ & Vector weights $\left(\mathrm{w}_{2}\right)$ \\
\hline$\overline{\mathbf{A F}}$ & 1 & 0.33 & 0.11 & 0.11 & 0.14 & 0.14 & 0.2 & 0.024 \\
\hline $\mathbf{E U}$ & 3 & 1 & 0.14 & 0.14 & 0.2 & 0.2 & 0.33 & 0.037 \\
\hline SE & 9 & 7 & 1 & 1 & 3 & 3 & 5 & 0.289 \\
\hline ID & 9 & 7 & 1 & 1 & 3 & 3 & 5 & 0.302 \\
\hline $\mathrm{CC}$ & 7 & 5 & 0.33 & 0.33 & 1 & 1 & 3 & 0.139 \\
\hline WQ & 7 & 5 & 0.33 & 0.33 & 1 & 1 & 3 & 0.139 \\
\hline \multirow[t]{5}{*}{ SA } & 5 & 3 & 0.2 & 0.2 & 0.33 & 0.33 & 1 & 0.069 \\
\hline & & & & & & & $\lambda \max$ & 7.327 \\
\hline & & & & & & & $\mathrm{CI}$ & 0.055 \\
\hline & & & & & & & RI & 1.35 \\
\hline & & & & & & & $\mathrm{CR}$ & 0.04 \\
\hline
\end{tabular}

Table 5: Degree of relative impact of evaluation criteria

\begin{tabular}{llllllll}
\hline & AF & EU & SE & ID & CC & WQ & SA \\
\hline AF & 0.5 & 0 & 0 & 0 & 0 & 0 & 0 \\
EU & 0.5 & 0.5 & 0 & 0.5 & 0.0455 & 0 & 0 \\
SE & 0 & 0.5 & 1 & 0 & 0.0455 & 0.0455 & 0.5 \\
ID & 0 & 0 & 0 & 0.5 & 0 & 0.0455 & 0 \\
CC & 0 & 0 & 0 & 0 & 0.5 & 0.409 & 0 \\
WQ & 0 & 0 & 0 & 0 & 0.409 & 0.5 & 0 \\
SA & 0 & 0 & 0 & 0 & 0 & 0 & 0.5 \\
\hline
\end{tabular}

The interdependence priorities of the criteria by synthesizing the results from previous two steps were calculated as follows: 


$$
w_{c}=\left[\begin{array}{c}
A F \\
E U \\
S E \\
I D \\
C C \\
W Q \\
S A
\end{array}\right]=\left[\begin{array}{ccccccc}
0.5 & 0 & 0 & 0 & 0 & 0 & 0 \\
0.5 & 0.5 & 0 & 0.5 & 0.455 & 0 & 0 \\
0 & 0.5 & 1 & 0 & 0.455 & 0.455 & 0.5 \\
0 & 0 & 0 & 0.5 & 0 & 0.455 & 0 \\
0 & 0 & 0 & 0 & 0.5 & 0.409 & 0 \\
0 & 0 & 0 & 0 & 0.409 & 0.5 & 0 \\
0 & 0 & 0 & 0 & 0 & 0 & 0.5
\end{array}\right]\left[\begin{array}{c}
0.024 \\
0.037 \\
0.289 \\
0.302 \\
0.139 \\
0.139 \\
0.069
\end{array}\right]=\left[\begin{array}{c}
0.012 \\
0.188 \\
0.355 \\
0.157 \\
0.126 \\
0.126 \\
0.035
\end{array}\right]
$$

In order to construct the decision matrix, the values given in Decision matrix valuessection were used for AF, SE, CC, WQ and SA. The decision makers were asked to evaluate the alternatives with respect to criterion using Saaty's 1-9 scale for EU and ID values. After the decision matrix is completed, normalized decision matrix (R) is constructed (Table 6) and using $\mathrm{w}_{\mathrm{c}}$ values a weighted normalized decision matrix is constructed (Table 7).

Table 6: Normalized decision matrix (R):

\begin{tabular}{llllllll}
\hline Alternatives & AF & EU & SE & ID & CC & WQ & SA \\
\hline Biomass & 0.9925 & 0.3181 & 0.3031 & 0.3515 & 0.3110 & 0.9587 & 0.9150 \\
Geothermal & 0.0000 & 0.3181 & 0.0650 & 0.3515 & 0.3446 & 0.1382 & 0.1350 \\
Hydraulic & 0.1158 & 0.6998 & 0.8660 & 0.4394 & 0.1093 & 0.0334 & 0.0433 \\
Solar & 0.0364 & 0.3817 & 0.1018 & 0.5712 & 0.8741 & 0.2453 & 0.3751 \\
Wind & 0.0124 & 0.4029 & 0.3789 & 0.4833 & 0.0925 & 0.0223 & 0.0433 \\
\hline
\end{tabular}

Table 7: Weighted normalized decision matrix

\begin{tabular}{llllllll}
\hline Alternatives & AF & EU & SE & ID & CC & WQ & SA \\
\hline Biomass & 0,0119 & 0,0597 & 0,1075 & 0,0555 & 0,0393 & 0,1212 & 0,0317 \\
Geothermal & 0,0000 & 0,0597 & 0,0230 & 0,0555 & 0,0436 & 0,0175 & 0,0047 \\
Hydraulic & 0,0014 & 0,1314 & 0,3071 & 0,0694 & 0,0138 & 0,0042 & 0,0015 \\
Solar & 0,0004 & 0,0717 & 0,0361 & 0,0902 & 0,1105 & 0,0310 & 0,0130 \\
Wind & 0,0001 & 0,0757 & 0,1344 & 0,0764 & 0,0117 & 0,0028 & 0,0015 \\
\hline
\end{tabular}

The ideal $\left(\mathrm{A}^{*}\right)$ and negative ideal $\left(\mathrm{A}^{-}\right)$solution sets defined by Equation (4) and Equation (5) are; $A^{*}=\{0,0.0597,0.3071,0.0555,0.0117,0.0028,0.0015\}$, $A^{-}=\{0.0119,0.1314,0.023,0.0902,0.1105,0.1212,0.0317\}$.

The separation measures and the relative closeness to the ideal solution were calculated using Equation (6), (7) and (8) and given in Table 8.

Table 8: Preference rankings

\begin{tabular}{lllll}
\hline Alternatives & S+ & S- & C* & Rank \\
\hline Biomass & 0.2359 & 0.1362 & 0.3659 & 3 \\
Geothermal & 0.2862 & 0.1498 & 0.3436 & 4 \\
Hydraulic & 0.0731 & 0.3243 & 0.8161 & 1 \\
Solar & 0.2924 & 0.1111 & 0.2754 & 5 \\
Wind & 0.1747 & 0.2013 & 0.5353 & 2 \\
\hline
\end{tabular}

As seen in Table 8, the most sustainable energy alternative for Turkey is hydraulic, followed by wind.
When we analyze the current energy generation and consumption patterns of Turkey, energy demand increases approximately $7 \%$ per year, but 
the supply does not increase at the same pace. The reliable production reserve seems to decrease to $4.5 \%$ in 2018 . Turkey produces $50 \%$ of its energy from imported natural gas and projections of Turkish Electricity Transmission Company (TEİAŞ) shows that this will decrease to $44 \%$ by year 2021 with the integration of nuclear power plants to the system. The share of renewable energy resources in the total energy supply is about $22,5 \%$. The share of hydraulic, wind, biomass and geothermal among renewable energy resources are $86.96 \%, 8.26 \%, 1.3 \%$ and $1.3 \%$ respectively [28]. The projections also do not indicate any change in these ratios. This situation shows that the institutions of Turkey are aware of the importance of hydraulic but the most important concern is short term supply security and they focus on the ability of the energy system to supply the energy need.

If we compare our results with the projections of TEIAS, the alternative rankings are the same but the shares are different. The best alternative for
Turkey is hydraulic followed by wind, biomass, geothermal and solar.

\section{Sensitivity Analysis}

Lastly a sensitivity analysis is conducted to measure how sensitive our results are with respect to changes in the criteria weights. The analysis is performed by exchanging each criterion's weight with another criterion's weight and calculating the relative closeness to ideal solution $\left(\mathrm{C}^{*}\right)$ for each alternative. The new $\mathrm{C}^{*}$ values are named as $\mathrm{C}_{12}$, $\mathrm{C}_{13}$, etc. where $\mathrm{C}_{12}$ is the case of weight change between criterion 1 and criterion 2 . The numbers indicating criteria are as such;

- Accident fatalities

- Energy use per capita

- Supply efficiency of energy

- Net import dependency

- Climate change

- Water quality

- Soil acidification

Table 9: Relative closeness values

\begin{tabular}{lccccc}
\hline & Biomass & Geothermal & Hydraulic & Solar & Wind \\
\hline $\mathbf{C}_{\mathbf{1 2}}$ & 0,2783 & 0,4433 & 0,9325 & 0,4090 & 0,6052 \\
$\mathbf{C}_{\mathbf{1 3}}$ & 0,2222 & 0,9129 & 0,8060 & 0,7629 & 0,9341 \\
$\mathbf{C}_{\mathbf{1 4}}$ & 0,3175 & 0,4275 & 0,8262 & 0,3920 & 0,5935 \\
$\mathbf{C}_{\mathbf{1 5}}$ & 0,3047 & 0,3915 & 0,8153 & 0,3726 & 0,5509 \\
$\mathbf{C}_{\mathbf{1 6}}$ & 0,3626 & 0,3662 & 0,8121 & 0,3195 & 0,5390 \\
$\mathbf{C}_{\mathbf{1 7}}$ & 0,3654 & 0,3457 & 0,8159 & 0,2810 & 0,5360 \\
$\mathbf{C}_{\mathbf{2 3}}$ & 0,4982 & 0,5498 & 0,6145 & 0,4460 & 0,6686 \\
$\mathbf{C}_{\mathbf{2 4}}$ & 0,3595 & 0,3385 & 0,8383 & 0,2662 & 0,5323 \\
$\mathbf{C}_{\mathbf{2 5}}$ & 0,3833 & 0,3544 & 0,8718 & 0,2464 & 0,5635 \\
$\mathbf{C}_{\mathbf{2 6}}$ & 0,3175 & 0,3866 & 0,8743 & 0,3262 & 0,5754 \\
$\mathbf{C}_{\mathbf{2 7}}$ & 0,2897 & 0,4056 & 0,9489 & 0,3151 & 0,5914 \\
$\mathbf{C}_{\mathbf{3 4}}$ & 0,4634 & 0,5572 & 0,7243 & 0,3838 & 0,6594 \\
$\mathbf{C}_{\mathbf{3 5}}$ & 0,5735 & 0,6297 & 0,8111 & 0,2707 & 0,8235 \\
$\mathbf{C}_{\mathbf{3 6}}$ & 0,2446 & 0,7322 & 0,8307 & 0,6148 & 0,8418 \\
$\mathbf{C}_{\mathbf{3 7}}$ & 0,2433 & 0,8498 & 0,8259 & 0,5752 & 0,9182 \\
$\mathbf{C}_{\mathbf{4 5}}$ & 0,3788 & 0,3525 & 0,8205 & 0,2699 & 0,5510 \\
$\mathbf{C}_{\mathbf{4 6}}$ & 0,3485 & 0,3681 & 0,8220 & 0,3069 & 0,5571 \\
$\mathbf{C}_{\mathbf{4 7}}$ & 0,3273 & 0,3969 & 0,8298 & 0,3197 & 0,5815 \\
$\mathbf{C}_{\mathbf{5 6}}$ & 0,3659 & 0,3436 & 0,8161 & 0,2754 & 0,5353 \\
$\mathbf{C}_{\mathbf{5 7}}$ & 0,3141 & 0,3669 & 0,8179 & 0,3158 & 0,5417 \\
$\mathbf{C}_{\mathbf{6 7}}$ & 0,3697 & 0,3386 & 0,8151 & 0,2453 & 0,5297 \\
\hline & & & & &
\end{tabular}




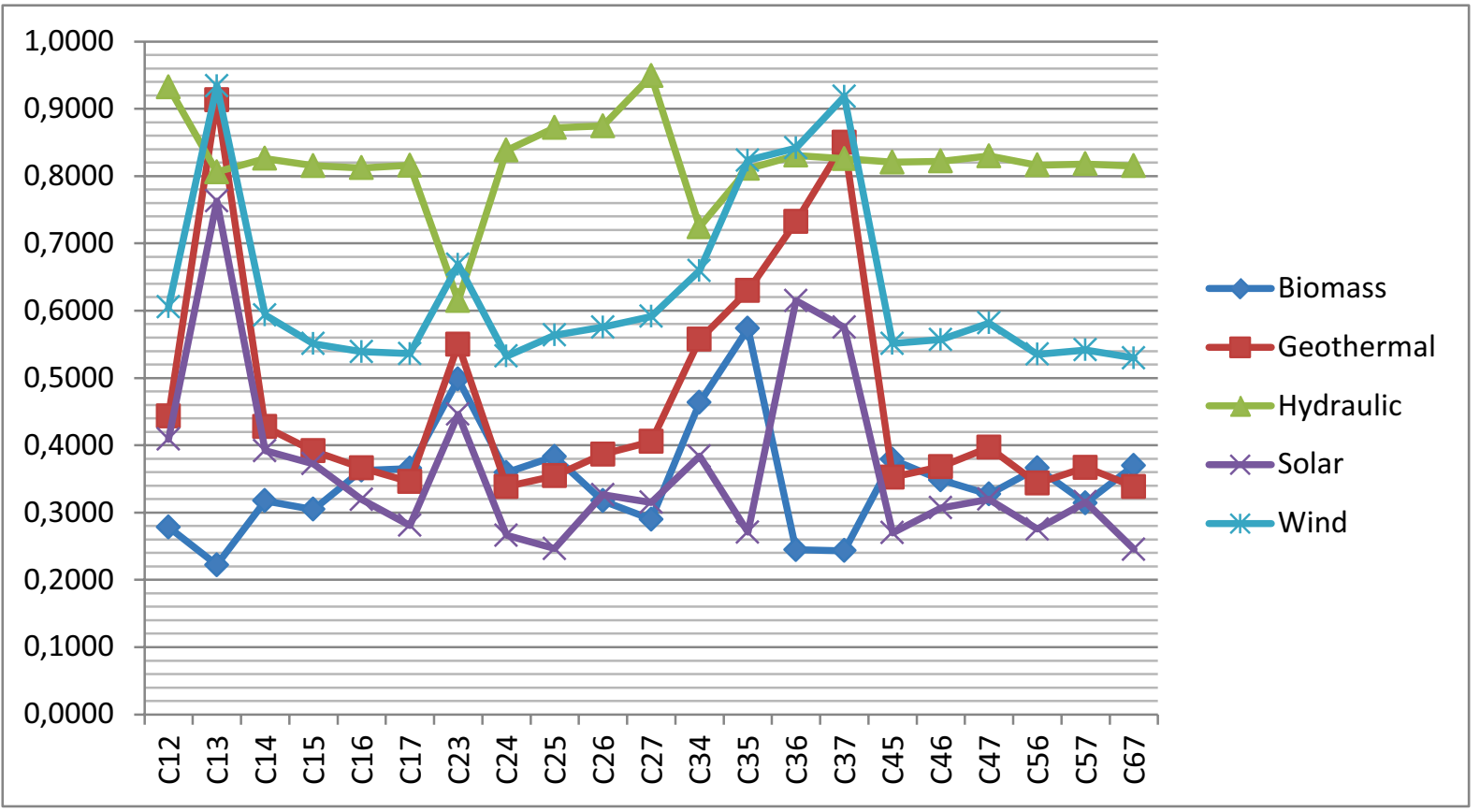

Fig. 3. Sensitivity analysis

Thus, $\mathrm{C} 12$ row in Table 9 shows the relative closeness values found as a result of TOPSIS when the weights of accident fatalities (0.012) and energy use per capita $(0.188)$ criteria exchanged. As the weight of accident fatalities increases and energy use decreases, the relative closeness value of biomass decreases and values of geothermal, hydraulic, solar and wind increase compared to the values we found in Table 8 . This result can be explained by the very low death rates of geothermal, hydraulic, solar and wind compared to biomass. The weights of other criteria were also pairwise exchanged and 21 different calculations were made which can also be interpreted in similar way. Table 9 summarizes the analysis results and Figure 3 displays the results on graph.

As seen in Figure 3, Hydraulic is the best alternative in $\mathrm{C}_{12}, \mathrm{C}_{14}, \mathrm{C}_{15}, \mathrm{C}_{16}, \mathrm{C}_{17}, \mathrm{C}_{24}, \mathrm{C}_{25}, \mathrm{C}_{26}$, $\mathrm{C}_{27}, \mathrm{C}_{34}, \mathrm{C}_{45}, \mathrm{C}_{46}, \mathrm{C}_{47}, \mathrm{C}_{56}, \mathrm{C}_{57}$ and $\mathrm{C}_{67}$ calculations. Wind becomes the best alternative in $\mathrm{C}_{13}, \mathrm{C}_{23}, \mathrm{C}_{35}$, $\mathrm{C}_{36}$ and $\mathrm{C}_{37}$ calculations. Thus when the relative importance of supply efficiency decreases and the relative importance of accident fatalities, energy use per capita or environmental impacts increase, the preference of the model shifts to wind, since the average energy efficiency coefficient of wind is less than hydro and for the other mentioned criteria wind performs better than hydro.

Figure 3 also showed us that in most of the cases hydraulic is the best alternative, followed by wind, geothermal, biomass and solar. However the sequence may change according to criteria weights. So, energy sector decision makers may choose the alternative to make investment more according to criteria importance.

\section{Conclusion}

Turkey as a candidate country for European Union membership must give increasing importance to sustainable development, and energy planning is one of the most important issues that must be considered in sustainable development plans. Although sustainability concept was being worked and there are many energy planning models in literature, there is no study that tries to build renewable energy perspective for Turkey using the EISD of IAEA to the best of our knowledge.

In this study, firstly the potentials of renewable energy resources were investigated and all the available (or potentially available) resources were included in the study. The impacts of the indicators on each other and the amount of these impacts were investigated, and it was seen that, the relations of the indicators form a network. A combined MCDM approach of ANP and TOPSIS was used in this paper since ANP was a useful method to compare the criteria and TOPSIS was used to rank alternatives. Also ANP enabled us to include both the objective values and expert opinions (qualitative data). As a result, the proposed method can 
be utilized to rank renewable energy alternatives to obtain a sustainable development perspective.

For further work, this study may be repeated using different decision making methods and the results may be compared.

\section{References}

1. International Atomic Energy Agency (IAEA), United Nations Department of Economic and Social Affairs (UNDESA), International Energy Agency (IEA), Eurostat, European Environment Agency (EEA), Energy indicators for sustainable development: guidelines and methodologies, International Atomic Energy Agency, Vienna, 2005, http://www.pub.iaea.org/MTCD /publications/PDF/Pub1222_web.pdf,(30.07.2013).

2. J.D.K. Bishop, G.A.J Amaratunga, C. Rodriguez, Using strong sustainability to optimize electricity generation fuel mixes, Energy Policy, 36 (2008)971-980.

3. J.D.K. Bishop, G.A.J. Amaratunga, C. Rodriguez, Linking energy policy, electricity generation and transmission using strong sustainability and cooptimization, Electric Power System Research, 80 (2010) 633-641.

4. J.R. San Cristóbal, Multi-criteria decision-making in the selection of a renewable energy project in Spain: The Vikor method, Renewable Energy, 36 (2011) 498-502.

5. T.L Saaty, Multicriteria Decision Making, RWS Publications, Pittsburgh, 1996.

6. Yoon, K.P., Hwang, C.L., Multiple Attribute Decision Making: An Introduction, Sage Publications, California, 1995.

7. Y.C. Erensal, E. Albayrak, Successful adoption of macro ergonomics in Manufacturing: Using a multicriteria decision-making methodology - Analytic Hierarchy Process, Human Factors in Ergonomics in Manufacturing, 14(4) (2004) 353-377.

8. L. Meade, J. Sarkis, Strategic analysis of logistics and supply chain management systems using the analytical network process, Transportation Research Part E: Logistics and Transportation Review, 34(3)(1998)201-215.

9. Y.C. Erensal, T. Gurbuz, Y.E. Albayrak, MultiCriteria Decision Model for Architecturing Competence in Human Performance Technology, International Journal Of Computational Intelligence Systems, 3(6) (2010) 815-831.

10. T.L. Saaty, Decision-making with the AHP: Why is the principal eigenvector necessary, European Journal of Operational Research, 145(1) (2003) 8591.

11. H.J. Shyur, COTS evaluation using modified TOPSIS and ANP. Applied Mathematics and Computation, 177 (2006) 251-259.

12. C.L. Hwang, K.P. Yoon, Multiple attribute decision-making: Methods and application, Springer, New York, 1981.
13. E. Triantaphyllou, Multi-Criteria Decision Making Methods: A Comparative Study, Kluwer Academic Publishers, Netherlands, 2000.

14. Özgür, M.A., Review of Turkey's Renewable Energy Potential, Renewable Energy, 33 (2008) 2345-2356.

15. Soyhan, H.S., Sustainable energy production and consumption in Turkey: A review, Renewable and Sustainable Energy Reviews, 13 (2009) 1350-1360.

16. MTA, General Directorate of Mineral Research and Exploration of Turkey, Available: http://www.mta.gov.tr/v1.0/daire_baskanliklari/ener ji/index.php?id=jeotermalpotansiyel, 13.06.2009.

17. Ulutaş, B.H., Determination of the appropriate energy policy for Turkey, Energy, 30 (2005) 11461161.

18. Dundar, C., Canbaz, M., Akgun, N., Ural, G., Turkey Wind Atlas, General Directorate of Electrical Power Resources Survey and Development Administration (EIE) \& Turkish State Meteorological Service (DMI), 975-6595-31-4, 2002.

19. Oğulata, R.T., Energy Sector and Wind Energy Potential in Turkey, Renewable and Sustainable Energy Reviews 7 (5) (2003) 469-484.

20. United Nations Department of Economic and Social Affairs (UNDESA) Division for Sustainable Development, Energy Indicators for Sustainable Development: Country Studies on Brazil, Cuba, Lithuania, Mexico, Russian Federation, Slovakia and Thailand, (2007) http://www.un.org/esa/ sustdev/publications/energy_indicators/ chapter2.pdf, (11.02.2011)

21. A. Kemmler, D. Spreng, Energy indicators for tracking sustainability in developing countries, Energy Policy, 35 (2007) 2466-2480.

22. P. Gipe Deaths per TWH by energy source, (2011) http://nextbigfuture.com/2011/03/deaths-per-twhby-energy-source.html, (10.06.2011).

23. Eurostat, Energy, Yearly Statistics (2008) 415-416, http://ec.europa.eu/eurostat (04.08.2010).

24. Eurostat, Environment and Energy, Data in focus, (2010) http://epp.eurostat.ec.europa.eu/cache/ITY OFFPUB/KS-QA-10-021/EN/KS-QA-10-021EN.PDF, (04.08.2010).

25. A.I. Chatzimouratidis, P.A. Pilavachi, Technological, economic and sustainability evaluation of power plants using the Analytic Hierarch Process. Energy Policy, 37 (2009) 778-787.

26. M. Pehnt, Dynamic life cycle assessment (LCA) of renewable energy technologies, Renewable Energy, 31 (2006) 55-71.

27. T.L. Saaty, Theory and Applications of the Analytic Network Process: Decision Making with Benefits, Opportunities, Costs, and Risks, RWS Publications, Pittsburg, 2009.

28. Turkish Electricity Transmission Company (TEİAŞ): "Türkiye Elektrik Enerjisi 10 Y1llık Üretim Kapasite Projeksiyonu (2012-2021)", December 2012, http://www.teias.gov.tr/KAPASITEPROJEKSIYON U2012.pdf, (02.06.2014). 